\title{
A Simple and Sensitive Assay of Gallic Acid Based on Localized Surface Plasmon Resonance Light Scattering of Silver Nanoparticles through Modified Tollens Process
}

\author{
Huiying WAng, ${ }^{* \dagger}$ Dinglong Chen, ${ }^{*}$ Yongju WeI, ${ }^{* *}$ Yongfang Chang, ${ }^{*}$ and Jianlu ZhaO* \\ *College of Chemical Engineering, Shijiazhuang University, Shijiazhuang 050035, P. R. China \\ **College of Chemistry and Material Science, Hebei Normal University, Shijiazhuang 050016, P. R. China
}

\begin{abstract}
A simple, low toxic, sensitive strategy based on the localized surface plasmon resonance light scattering (LSPR-LS) properties of silver nanoparticles (AgNPs) is introduced for the detection of gallic acid (GA). It was found that the silver ammonium complex, $\left[\mathrm{Ag}\left(\mathrm{NH}_{3}\right)_{2}\right]^{+}(\mathrm{aq})$, could be reduced in the alkaline medium by GA at room temperature; this reaction formed dispersed AgNPs. Transmission electron microscopy analyses were performed to ascertain the formation of AgNPs. UV-visible spectra revealed the localized surface plasmon resonance (LSPR) absorption at $410 \mathrm{~nm}$ corresponding to the LSPR of AgNPs. On these basis, we could quantify the GA concentration in the range of $4 \times 10^{-7}-5 \times 10^{-6} \mathrm{~mol} \mathrm{~L}^{-1}$ in the optimized experimental conditions. This method was used for determining the concentration of GA in artificial samples with satisfactory results. The detailed mechanism underlying this special phenomenon was elucidated.
\end{abstract}

(Received May 4, 2011; Accepted July 19, 2011; Published September 10, 2011)

\section{Introduction}

Metal nanoparticles (NPs) have been extensively investigated because of their unique electronic and optical properties that are substantially distinct from those of both the bulk phase and individual molecules. ${ }^{1-5}$ Much effort has been, in particular, devoted to investigate the properties of localized surface plasmon resonance (LSPR), which can be attributed to the collective oscillation of conduction electrons that is induced by an electromagnetic field. Part of the reason lies in the fact that these colloidal particles can form a strongly enhanced LSPR light scattering (LS), especially silver nanoparticles (AgNPs), which are obviously different from those nanoparticles made of gold and other noble metals. For example, the magnitude of LS from 80 -nm gold nanoparticles (AuNPs) is 5 orders higher than the light emission from strongly fluorescing dyes such as fluorescein; as to the scattering properties, the AgNPs are superior to the AuNPs of the same size..$^{6-8}$

As a result, it has been reported recently that AgNPs, especially for the applications of the scattered light for sensing, is a promising alternative to AuNPs in many applications in the fields of medicine, microbiology, and analytical chemistry. ${ }^{9-12}$ As far as we know, however, relatively few studies have focused on the detection purposes via the formed AgNPs, which is a simple and low toxic approach to the overall process of determinations. ${ }^{13,14}$

Gallic acid (GA; 3,4,5-trihydroxybenzoic acid; for structure see Fig. 1), a naturally occurring plant phenol, is an important constituent of traditional Chinese medicine and black tea. ${ }^{15,16}$ GA is commonly used in the industries of pharmaceuticals, food

$\dagger$ To whom correspondence should be addressed.

E-mail: wanghuiying@ @jzc.edu.cn and cosmetics. It is a strong natural antioxidant that helps to protect our cells against oxidative damage and has been pharmacologically active as an antifungal, antivira, anticarcinogenic, antiatherosclerotic, and antiinflammatory agent in a variety of in vivo and in vitro studies. GA is found to show cytotoxicity against cancer cells without harming healthy cells, and can be used as a remote astringent in cases of internal hemorrhage. GA is also used to treat albuminuria and diabetes. However, higher concentration of GA acts as a prooxidant.

Owing to its pharmacological activity, it is necessary to develop a simple and sensitive determination method. In the last few years, a number of analytical methodologies have been utilized to develop the GA detection, including UV-vis spectrophotometry, ${ }^{17}$ chemiluminescence, ${ }^{18}$ and high performance liquid chromatography (HPLC). ${ }^{19,20}$ Some of the above methods, however, are insensitive or require expensive reagents or are time-consuming.

Thanks to the connection of LSPR-LS with metal NPs, it can overcome those drawbacks described above. LSPR-LS spectroscopy is a new, simple, rapid, and sensitive spectral technique, ${ }^{10,11,13,14,21}$ and it can be recorded on a conventional fluorometer by simply setting the synchronous mode $(\Delta \lambda=0)$. Since metal nanoparticles are found to exhibit strong LSPR-LS<smiles>O=C(O)c1cc(O)c(O)c(O)c1</smiles>

Fig. 1 The chemical structure of the gallic acid. 
signals, LSPR-LS has now become an effective technique in the quantitative determination of metal NPs, especially AgNPs, it exhibits high sensitivity, relatively low cost, direct monitoring and simplicity.

Herein, we report a novel and simple strategy for the determination of GA using LSPR-LS signals resulting from the formed AgNPs. It was found that, in strong alkaline solutions, GA acted as both a reducing agent and a stabilizer, and was capable of reducing silver ammonium complex, $\left[\mathrm{Ag}\left(\mathrm{NH}_{3}\right)_{2}\right]^{+}(\mathrm{aq})$, known as the "silver mirror" reaction or Tollens process, generating highly dispersed AgNPs at room temperature. It was found that there was a good linear relationship of the LSPR-LS intensities and concentrations of GA. On this basis, we could quantify the GA concentration in the range of $4 \times 10^{-7}$ $5 \times 10^{-6} \mathrm{~mol} \mathrm{~L}^{-1}$ in the optimized experimental conditions. Our analytical data indicated that the recovery and precision of the method applied to determine GA directly in artificial samples were satisfactory. The results of the assay could be measured and quantified with a common spectrofluorometer and, in some cases, visually monitored with the unaided eye.

\section{Experimental}

\section{Reagents and chemicals}

All the reagents were of analytical reagent grade unless specified; doubly distilled water was used throughout, if necessary, the boiled distilled water was also used.

GA was commercially purchased from Tianjin Yongda Reagent Development Center (Tianjin, China). Silver nitrate was supplied by Tianjin Kermel Chemical Reagent (Tianjin, China) and ammonia by Shijiazhuang Huadi Chemical (Shijiazhuang, China). A stock solution of GA $\left(1 \times 10^{-5} \mathrm{~mol} \mathrm{~L}^{-1}\right)$ was stored in the refrigerator $\left(4^{\circ} \mathrm{C}\right)$. Working standard solutions were prepared daily from the stock solution by appropriate dilution before use. A $1 \times 10^{-3} \mathrm{~mol} \mathrm{~L}^{-1} \mathrm{AgNO}_{3}$ solution was prepared daily.

\section{Apparatus}

The LSPR-LS spectra and intensities were measured with a Hitachi F-4500 fluorescence spectrophotometer (Hitachi, Tokyo, Japan) from 300 to $700 \mathrm{~nm}$ by simultaneously scanning the excitation and emission monochromators with same starting wavelength for the excitation and emission (namely, $\Delta \lambda=$ $0 \mathrm{~nm}$ ). The LSPR absorption was recorded on a U-3010 spectrophotometer (Hitachi, Japan). A vortex mixer, MVS-1 (Jinbeide, Beijing, China), was employed to blend the solution.

Transmission electron microscopy (TEM) images of the AgNPs were taken on an H-7500 electron microscope (Hitachi, Japan) using an $80-\mathrm{kV}$ accelerating voltage at $200 \mathrm{k}$ magnification. Specimens were prepared by placing drops from solutions of the AgNPs on a carbon-coated copper grid. The films on the copper grids were allowed to stand for $5 \mathrm{~min}$, following which the extra solution was removed using a piece of blotting paper, and the grid was allowed to dry prior to measurement.

\section{Procedure}

Volumes of $2.5 \mathrm{~mL}$ of $1.0 \times 10^{-3} \mathrm{~mol} \mathrm{~L}^{-1} \mathrm{AgNO}_{3}, 100 \mu \mathrm{L}$ of $0.01 \mathrm{~mol} \mathrm{~L}^{-1} \mathrm{NaOH}$, and $80 \mu \mathrm{L}$ of $0.25 \mathrm{~mol} \mathrm{~L}^{-1} \mathrm{NH}_{3} \cdot \mathrm{H}_{2} \mathrm{O}$ were mixed, and the mixture (namely, $\left[\mathrm{Ag}\left(\mathrm{NH}_{3}\right)_{2}\right]^{+}$) was stirred thoroughly. Then a certain concentration of GA solution was added into the mixture. At last, the mixture was diluted to $5.0 \mathrm{~mL}$ with the doubly distilled water, and blended thoroughly again. Thirty minutes later, the LSPR absorption and LSPR-LS

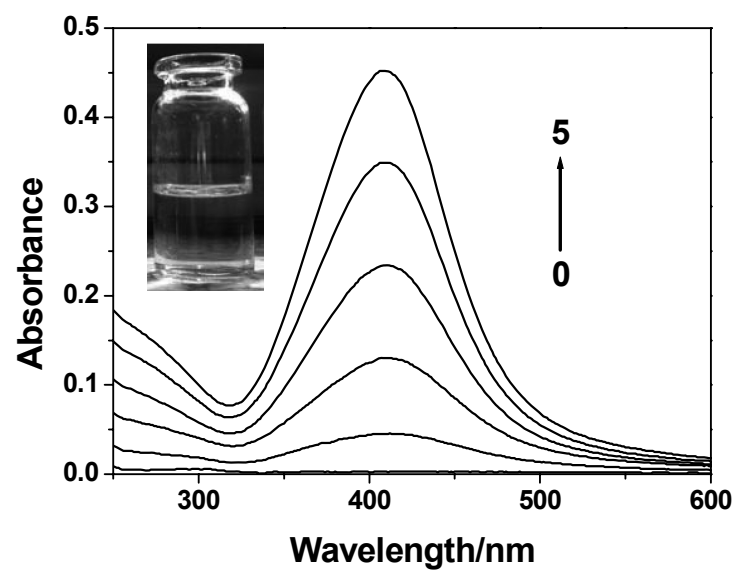

Fig. 2 The LSPR absorption of the AgNPs resulting from the redox reaction between $\left[\mathrm{Ag}\left(\mathrm{NH}_{3}\right)_{2}\right]^{+}$in the alkaline medium and different concentrations of GA under optimal experimental conditions. The insert shows the color for the visible sensing detection in response to $5 \mu \mathrm{mol} \mathrm{L}{ }^{-1}$ of GA. Concentrations: $\mathrm{AgNO}_{3}, 5 \times 10^{-4} \mathrm{~mol} \mathrm{~L}-1 ; \mathrm{NaOH}$, $2 \times 10^{-4} \mathrm{~mol} \mathrm{~L}^{-1} ; \mathrm{NH}_{3} \cdot \mathrm{H}_{2} \mathrm{O}, 4 \times 10^{-3} \mathrm{~mol} \mathrm{~L}^{-1}$; GA (from curves 0 to 5 , $\left.\mu \mathrm{mol} \mathrm{L}{ }^{-1}\right), 0,1,2,3,4,5$.

spectra were recorded against the reagent blank solution treated in the same way without GA. The LSPR-LS spectra were obtained by keeping the slit width of the excitation and emission of the spectrofluorometer at $5.0 \mathrm{~nm}$ and the PMT voltage at $400 \mathrm{~V}$.

\section{Results and Discussion}

The spectral characteristics of the redox reaction between GA and $\left[\mathrm{Ag}\left(\mathrm{NH}_{3}\right)_{2}\right]^{+}$

UV-vis absorption spectroscopy was first utilized to characterize the absorption band of products. While GA was added, the mixture became yellowish (Fig. 2 insert picture) and a new narrow absorption peak appeared near $410 \mathrm{~nm}$. This is a typical feature of the absorption of metallic AgNPs ascribed to the LSPR absorption, indicating the presence of AgNPs in the solution. Figure 2 displays the LSPR absorption spectra of reaction process using different concentrations of GA. The results showed that the LSPR absorption intensity increased with increasing GA concentration at the position of $410 \mathrm{~nm}$.

Figure 3 shows the LSPR-LS spectra of the redox reaction between $\mathrm{GA}$ and $\left[\mathrm{Ag}\left(\mathrm{NH}_{3}\right)_{2}\right]^{+}$detected with a common spectrofluorometer. We can see that a scattering peak is located around $476 \mathrm{~nm}$; this belongs to the LSPR absorption region of $350-500 \mathrm{~nm}$, so the light scattering of the AgNPs is ascribed to the LSPR-LS and the signals we measured are properly identified. When one considers the relationship between the absorption spectra and the light scattering spectra, the LSPR-LS spectra can also demonstrate the formation of AgNPs from another point of view, and the process of the formed AgNPs is correlative to the presence of GA. Figure 3 shows that the LSPR-LS intensity of GA blank solution is quite weak. After the reaction with $\left[\mathrm{Ag}\left(\mathrm{NH}_{3}\right)_{2}\right]^{+}$and the formation of AgNPs, the LSPR-LS intensity got enhanced. What is more, the LSPR-LS intensities increased with increasing the GA concentrations. So a quantitative analytical method for the detection of GA can be constructed.

To confirm the formation of AgNPs, we carried out TEM studies. The TEM image is represented in Fig. 4. TEM images 


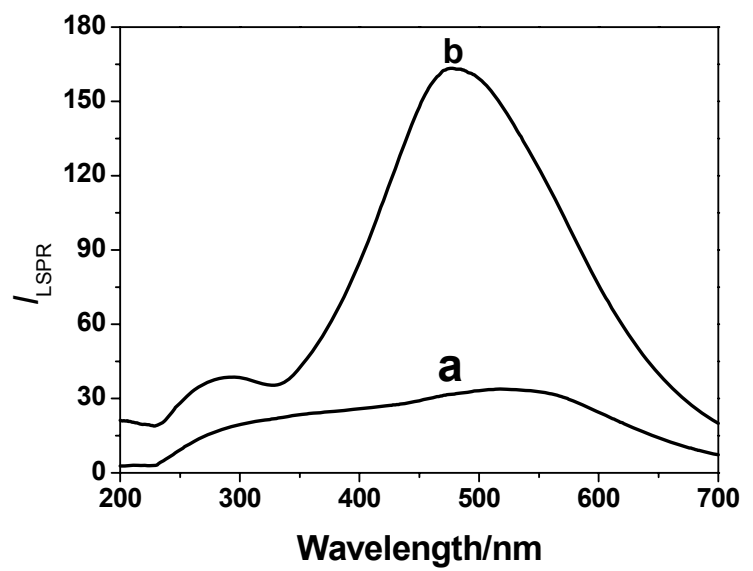

Fig. 3 Variation in the LSPR-LS spectra of the formed AgNPs solution at different concentrations of GA: (a) 0 ; (b) $3 \mu \mathrm{mol} \mathrm{L}^{-1}$ under optimal experimental conditions. Concentrations: $\mathrm{AgNO}_{3}, 5 \times$ $10^{-4} \mathrm{~mol} \mathrm{~L}^{-1} ; \mathrm{NaOH}, 2 \times 10^{-4} \mathrm{~mol} \mathrm{~L}^{-1} ; \mathrm{NH}_{3} \cdot \mathrm{H}_{2} \mathrm{O}, 4 \times 10^{-3} \mathrm{~mol} \mathrm{~L}^{-1}$.

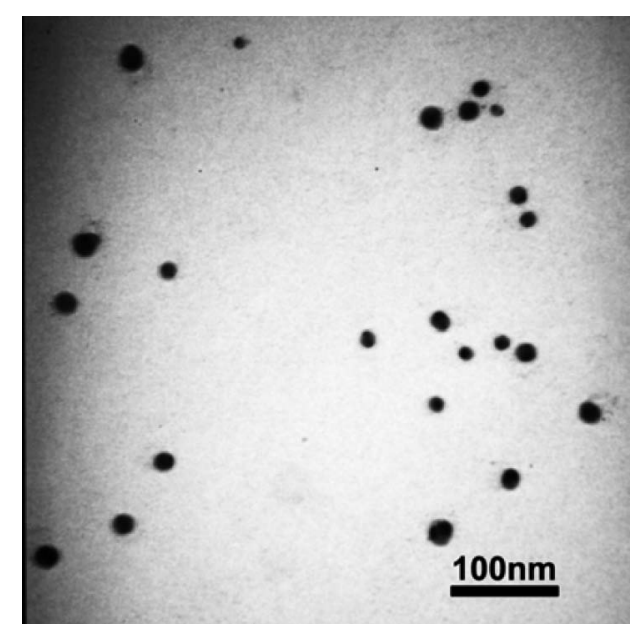

Fig. 4 Typical TEM image of the formed AgNPs in an aqueous system using GA as reducing agent and silver ammonium complex as precursor via redox reaction at room temperature. Concentrations: $\mathrm{AgNO}_{3}, 5 \times 10^{-4} \mathrm{~mol} \mathrm{~L}^{-1} ; \mathrm{NaOH}, 2 \times 10^{-4} \mathrm{~mol} \mathrm{~L}^{-1} ; \mathrm{NH}_{3} \cdot \mathrm{H}_{2} \mathrm{O}, 4 \times$ $10^{-3} \mathrm{~mol} \mathrm{~L}^{-1}$; GA, $2 \mu \mathrm{mol} \mathrm{L}{ }^{-1}$.

reveal uniform produced AgNPs with an average size of about $20 \mathrm{~nm}$. This observation is consistent with the observation of an LSPR absorbance band and LSPR-LS for the formed nanoparticles (Figs. 2 and 3, curves 2 and b, respectively).

\section{Optimization of experimental conditions}

For the experiments to achieve an optimal LSPR-LS signaling, the concentration of $\mathrm{NaOH}$ was very crucial, since the strong LSPR-LS signal of the AgNPs occurs only in an alkaline medium and strongly depends on the concentration of $\mathrm{NaOH}$. Therefore, the influence of $\mathrm{NaOH}$ concentration on the reaction was examined over the range 0 to $5 \times 10^{-4} \mathrm{~mol} \mathrm{~L}^{-1}$, as shown in Fig. 5a. The maximal net peak height $(\Delta I$ at $476 \mathrm{~nm})$ of LSPR-LS was observed for $2 \times 10^{-4} \mathrm{~mol} \mathrm{~L}^{-1}$ concentration of $\mathrm{NaOH}$. Thus, this value was selected for further studies.

The addition of $\mathrm{NaOH}$, although providing high alkalinity for the ionization of the phenol group, makes the silver cations deposit and thus greatly weakens the oxidation capacity of
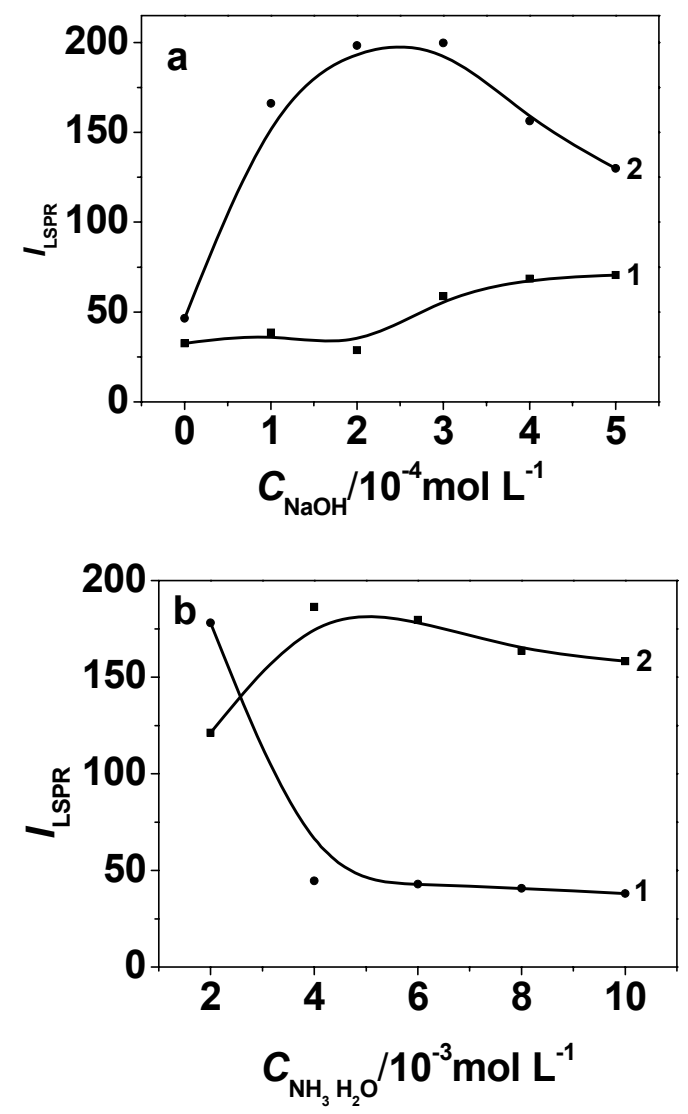

Fig. 5 Effects of reaction conditions on the LSPR-LS intensity. (a) $\mathrm{NaOH}$ concentration: $\mathrm{AgNO}_{3}, 5 \times 10^{-4} \mathrm{~mol} \mathrm{~L}^{-1} ; \mathrm{NH}_{3} \cdot \mathrm{H}_{2} \mathrm{O}, 4 \times$ $10^{-3} \mathrm{~mol} \mathrm{~L}^{-1}$; GA, 0 (curve 1), $3 \mu \mathrm{mol} \mathrm{L}^{-1}$ (curve 2). (b) Ammonia concentration: $\mathrm{AgNO}_{3}, 5 \times 10^{-4} \mathrm{~mol} \mathrm{~L}^{-1} ; \mathrm{NaOH}, 2 \times 10^{-4} \mathrm{~mol} \mathrm{~L}^{-1}$; GA, 0 (curve 1), $3 \mu \mathrm{mol} \mathrm{L}^{-1}$ (curve 2).

$\mathrm{AgNO}_{3}$. Inspired by Tollens' reagent, we employed silver ammonia ion as an oxidant. For this reason, the effect of ammonia concentration was tested within the range of $2-10 \mathrm{mmol} \mathrm{L}^{-1}$. With the increase of the concentration of ammonia, $\Delta I$ intensity increased and reached a maximum when $4 \mathrm{mmol} \mathrm{L}^{-1}$ ammonia was used for the determination of GA; thereafter it decreased slightly (Fig. 5b). Thus, these values were selected for further studies.

\section{Analytical parameters}

With the optimized experimental conditions as mentioned above, working curves were obtained (Fig. 6). The $\Delta I$ at $476 \mathrm{~nm}$ $\left(\Delta I_{476 \mathrm{~nm}}\right)$ was linearly proportional to the $\mathrm{GA}\left(c, \mu \mathrm{mol} \mathrm{L} \mathrm{L}^{-1}\right)$ $(n=9)$ in the range of $0.4-5.0 \mu \mathrm{mol} \mathrm{L}^{-1}$ (Fig. 6 insert picture). The regression equation was obtained as $\Delta I=46.96 c-8.90$ $(r=0.9923)$ for GA. The relative standard deviation (RSD) for 10 determinations was $3.9 \%$ for $2 \mu \mathrm{mol} \mathrm{L} \mathrm{L}^{-1} \mathrm{GA}$. The detection limit as signal to noise ratio of 3 was $1 \times 10^{-7} \mathrm{~mol} \mathrm{~L}^{-1}$.

\section{Possible mechanism of the redox reactions}

It is proposed here that GA have a capacity for reducing $\left[\mathrm{Ag}\left(\mathrm{NH}_{3}\right)_{2}\right]^{+}$in the alkaline medium (better known as the Ag mirror reaction). We think that the capacity partly depends on the presence of the silver oxide $\left(\mathrm{Ag}_{2} \mathrm{O}\right)$, because we found that AgNPs could not form when $\mathrm{Ag}^{+}$instead of $\left[\mathrm{Ag}\left(\mathrm{NH}_{3}\right)_{2}\right]^{+}$was used as the silver source. On the one hand, though the formation of an $\left[\mathrm{Ag}\left(\mathrm{NH}_{3}\right)_{2}\right]^{+}$complex cation in the presence of a 




Fig. 6 Changes in the LSPR-LS spectra of the AgNPs resulting from the reaction of $\mathrm{AgNO}_{3}$ and different concentrations of GA under optimal experimental conditions. The inserted is the calibration curve of the GA under optimal conditions. Concentrations: $\mathrm{AgNO}_{3}, 5 \times$ $10^{-4} \mathrm{~mol} \mathrm{~L}^{-1} ; \mathrm{NaOH}, 2 \times 10^{-4} \mathrm{~mol} \mathrm{~L}^{-1} ; \mathrm{NH}_{3} \cdot \mathrm{H}_{2} \mathrm{O}, 4 \times 10^{-3} \mathrm{~mol} \mathrm{~L}^{-1} ; \mathrm{GA}$ (from curves 0 to $9, \mu \mathrm{mol} \mathrm{L}^{-1}$ ), $0,0.4,0.8,1,1.5,2,2.5,3,4,5$.

sufficiently high ammonia concentration leads to a decrease in the $\mathrm{Ag}^{+} / \mathrm{Ag}$ standard redox potential from $+0.799 \mathrm{~V} v s$. SHE for uncomplexed $\mathrm{Ag}^{+} / \mathrm{Ag}$ down to $+0.38 \mathrm{~V}$ vs. SHE for $\left[\mathrm{Ag}\left(\mathrm{NH}_{3}\right)_{2}\right]^{+}$, we found that the resulting solution of $\mathrm{GA}$ and $\left[\mathrm{Ag}\left(\mathrm{NH}_{3}\right)_{2}\right]^{+}$ changed to yellow color, indicating that the redox reaction occurred. The TEM image (Fig. 4) confirms the presence of AgNPs in the solution. On the other hand, the redox potential of GA is $+0.5 \mathrm{~V} v s$. SHE; ${ }^{22}$ hence, the reduction of silver diamine is thermodynamically unfavorable at room temperature. For these reasons, we inferred that $\mathrm{Ag}_{2} \mathrm{O}$ is crucial in the formation of AgNPs based on the redox reaction of GA and $\left[\mathrm{Ag}\left(\mathrm{NH}_{3}\right)_{2}\right]^{+}$. The formation of $\mathrm{Ag}_{2} \mathrm{O}$ could greatly increase the nucleation rate of AgNPs by providing nucleation sites and forming a large number of seeds. $\mathrm{Ag}_{2} \mathrm{O}$ is formed in the presence of a small amount of hydroxide ions in the reaction system; the $\mathrm{Ag}_{2} \mathrm{O}$ produced must also be in the colloid form since no precipitation is observed in the subsequent reduction of $\left[\mathrm{Ag}\left(\mathrm{NH}_{3}\right)_{2}\right]^{+}$(Fig. 2, curve 0).

On the basis of the UV-vis (Fig. 2) and LSPR-LS studies (Fig. 3), we propose that the AgNPs are stabilized through electrostatic interactions between the charged particles and the capping agent, which is the carboxylic group and its oxidized form present in GA as represented in Fig. 1. TEM study indicates that the AgNPs are more or less spherical in shape, having an average diameter of $20 \mathrm{~nm}$. Thus, GA played multiple roles in the formation of silver nanocolloids: to reduce the $\left[\mathrm{Ag}\left(\mathrm{NH}_{3}\right)_{2}\right]^{+}$to form metal silver atoms, and at the same time to prevent agglomeration of AgNPs through steric hindrance.

Based on these experimental results and on previous studies ${ }^{22-25}$ a GA reduction-capping/AgNPs formation mechanism is given in Fig. 7. The process mainly involves three steps. In the first step, silver nitrate reacted with $\mathrm{NaOH}$ molecules to form $\mathrm{Ag}_{2} \mathrm{O}$ as described in Eq. (1), resulting in the formation of small nuclei. In the second step, the free $\mathrm{Ag}^{+}$(Eq. (2)) dissociated from silver ammonia complex (Eq. (3)) could adsorb on the surfaces of $\mathrm{Ag}_{2} \mathrm{O}$, reduced by $\mathrm{GA}$ to $\mathrm{Ag}^{0}$, and individual Ag clusters agglomerate to form AgNPs. In the third step, Ostwald ripening of aggregates led to a breakdown and redispersion of the AgNPs with a uniform size, which were protected by the oxidized form of GA.

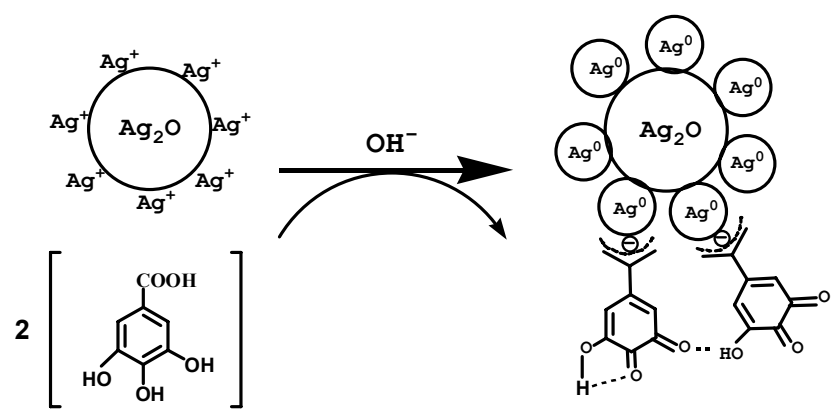

Fig. 7 Schematic illustration representing the mechanism of the formation of AgNPs upon GA addition in the alkaline medium.

Table 1 Tolerance of foreign biological substances

\begin{tabular}{lcc}
\hline Substance & $\begin{array}{c}\text { Concentration/ } \\
\mu \mathrm{mol} \mathrm{L}{ }^{-1}\end{array}$ & $\begin{array}{c}\text { Relative error, } \\
\%\end{array}$ \\
\hline Uric acid & 5 & -9.9 \\
Glucose & 2 & -3.0 \\
Sucrose & 5 & +4.4 \\
Lactose & 5 & -5.0 \\
Ascorbic acid & 0.5 & +9.6 \\
$\mathrm{~K}^{+}, \mathrm{Cl}^{-}$ & 50 & -4.4 \\
$\mathrm{Mg}^{2+}, \mathrm{SO}_{4}^{2-}$ & 50 & -2.6 \\
$\mathrm{Na}^{+}, \mathrm{PO}_{4}^{3-}$ & 50 & +4.7 \\
$\mathrm{Ba}^{2+}, \mathrm{Cl}^{-}$ & 50 & +3.4 \\
$\mathrm{Ca}^{2+}, \mathrm{Cl}^{-}$ & 50 & -4.8 \\
$\mathrm{Zn}^{2+}, \mathrm{SO}_{4}^{2-}$ & 30 & -3.9 \\
$\mathrm{Al}^{3+}, \mathrm{SO}_{4}^{2-}$ & 30 & -4.0 \\
\hline
\end{tabular}

$\lambda_{\max }, 476 \mathrm{~nm}$.

Concentrations: $\mathrm{AgNO}_{3}, 5 \times 10^{-4} \mathrm{~mol} \mathrm{~L}^{-1}$; $\mathrm{NaOH}, 2 \times 10^{-4} \mathrm{~mol} \mathrm{~L}^{-1}$; $\mathrm{NH}_{3} \cdot \mathrm{H}_{2} \mathrm{O}, 4 \times 10^{-3} \mathrm{~mol} \mathrm{~L}^{-1}$; GA, $2 \mu \mathrm{mol} \mathrm{L}^{-1}$.

$$
\begin{aligned}
& 2 \mathrm{AgNO}_{3}+2 \mathrm{NaOH}=\mathrm{Ag}_{2} \mathrm{O}+2 \mathrm{NaNO}_{3}+\mathrm{H}_{2} \mathrm{O} \\
& {\left[\mathrm{Ag}\left(\mathrm{NH}_{3}\right)_{2}\right]^{+} \rightleftharpoons \mathrm{Ag}^{+}+2 \mathrm{NH}_{3}} \\
& \mathrm{Ag}_{2} \mathrm{O}+4 \mathrm{NH}_{3}+\mathrm{H}_{2} \mathrm{O}=2\left[\mathrm{Ag}\left(\mathrm{NH}_{3}\right)_{2}\right]^{+}+2 \mathrm{OH}^{-}
\end{aligned}
$$

\section{Interference study}

The influence of some possibly coexisting foreign inorganic ions and organic compounds were examined for the analysis of practical samples, especially in serum and uric samples. The tolerance limits for various foreign species in the determination of $2 \mu \mathrm{mol} \mathrm{L}{ }^{-1} \mathrm{GA}$ by the described procedure were studied. In the process of determination, $2 \mu \mathrm{mol} \mathrm{L} \mathrm{L}^{-1}$ of GA was added to each sample and the other interferential species was added subsequently. The influence of 12 foreign coexisting substances: uric acid, glucose, sucrose, lactose, ascorbic acid, $\mathrm{K}^{+}, \mathrm{Mg}^{2+}$, $\mathrm{Na}^{+}, \mathrm{Ba}^{2+}, \mathrm{Ca}^{2+}, \mathrm{Zn}^{2+}$, and $\mathrm{Al}^{3+}$ on the LSPR-LS determination of $2 \mu \mathrm{mol} \mathrm{L}{ }^{-1} \mathrm{GA}$ was considered. Table 1 shows that the relative error of most species is within the range of $5.0 \%$. Only uric acid and ascorbic acid generated weak interfering LSPR-LS intensity; this corresponded to about less than $10 \%$ of the signal for GA. Therefore, the proposed approach has good selectivity for GA and can be used for the following determinations in artificial samples.

\section{Results of determination for artificial samples}

To evaluate the applicability of the proposed method, LSPR-LS determination in artificial samples was performed according to 
Table 2 Analytical results of the direct determination of GA in artificial samples

\begin{tabular}{cccccc}
\hline $\begin{array}{c}\text { Sample } \\
\text { No. }\end{array}$ & $\begin{array}{c}\text { Main } \\
\text { interference }\end{array}$ & $\begin{array}{c}\text { GA } \\
\text { containing } \\
\text { in samples/ } \\
\mu m o l ~ L^{-1}\end{array}$ & $\begin{array}{c}\text { Average } \\
\text { found } /\end{array}$ & $\begin{array}{c}\text { Recovery, } \\
\%\end{array}$ & $\begin{array}{c}\text { RSD, } \\
\%\end{array}$ \\
\hline 1 & $\mathrm{Ba}^{2+}, \mathrm{Na}^{+}$, sucrose & 2.00 & 1.91 & 95.5 & 4.7 \\
2 & $\mathrm{Ca}^{2+}, \mathrm{K}^{+}$, glucose & 2.00 & 2.06 & 103.0 & 3.9 \\
\hline
\end{tabular}

$\lambda_{\max }, 476 \mathrm{~nm}$.

a. Concentrations ( $\mu$ mol L ${ }^{-1}$ ): $\mathrm{Ba}^{2+}, 100 ; \mathrm{Na}^{+}, 100$; sucrose, $10 ; \mathrm{Ca}^{2+}$, $10 ; \mathrm{K}^{+}, 200 ;$ glucose, $10 ; \mathrm{AgNO}_{3}, 5 \times 10^{-4} \mathrm{~mol} \mathrm{~L}^{-1} ; \mathrm{NaOH}$, $2 \times 10^{-4} \mathrm{~mol} \mathrm{~L}^{-1} ; \mathrm{NH}_{3} \cdot \mathrm{H}_{2} \mathrm{O}, 4 \times 10^{-3} \mathrm{~mol} \mathrm{~L}^{-1}$.

b. All the values were the average of five measurements obtained.

the described procedures. The detected GA content in artificial samples was derived from the standard curve and the regression equation. The average recovery test was performed by using the standard addition method, and RSD values were generally good as obtained from a series of two artificial samples. The recovery data shown in Table 2 confirmed the accuracy of the developed LSPR-LS method and the absence of interfering matrix effects.

\section{Conclusions}

A novel and simple technique for the detection of GA using AgNPs coupled to LSPR-LS has been developed. This method is relatively sensitive, environmentally benign, and can easily be extended to other systems and expand the range of application. Also, based on the modified Tollens process strategy, a possible mechanism of AgNPs formation and stabilization was proposed. GA served as reducing reagent and simultaneously acted as stabilizers. At the same time, the formation of $\mathrm{Ag}_{2} \mathrm{O}$ is crucial to the redox reaction. The LSPR-LS-based simple and low toxic method demonstrated here may open up new possibilities for pharmaceutical assays and environmental analyses. In addition, a colorimetric method for the polyphenol detection could be proposed based on the change of the obvious color of this kind of AgNPs. Moreover, investigation of the plant phenol (such as GA) compounds by means of nanotechnology techniques has the potential for providing valuable insights into the "green synthese" in nano field.

\section{References}

1. N. L. Rosi and C. A. Mirkin, Chem. Rev., 2005, 105, 1547.
2. D. A. Giljohann, D. S. Seferos, W. L. Daniel, M. D. Massich, P. C. Patel, and C. A. Mirkin, Angew. Chem., Int. Ed., 2010, 49, 3280.

3. M. Rycenga, C. M. Cobley, J. Zeng, W. Li, C. H. Moran, Q. Zhang, D. Qin, and Y. Xia, Chem. Rev., 2011, 111, 3669.

4. J. E. Millstone, S. J. Hurst, G. S. Métraux, J. I. Cutler, and C. A. Mirkin, Small, 2009, 5, 646.

5. C. M. Cobley, S. E. Skrabalak, D. J. Campbell, and Y. Xia, Plasmonics, 2009, 4, 171.

6. P. K. Jain, K. S. Lee, I. H. El-Sayed, and M. A. El-Sayed, J. Phys. Chem. B, 2006, 110, 7238.

7. J. Yguerabide and E. E. Yguerabide, Anal. Biochem., 1998, 262, 137.

8. J. Yguerabide and E. E. Yguerabide, Anal. Biochem., 1998, $262,157$.

9. X. Xu, D. G. Georganopoulou, H. D. Hill, and C. A. Mirkin, Anal. Chem., 2007, 79, 6650.

10. J. Ling, Y. F. Li, and C. Z. Huang, Anal. Chem., 2009, 81, 1707.

11. L. Q. Chen, S. J. Xiao, L. Peng, T. Wu, J. Ling, Y. F. Li, and C. Z. Huang, J. Phys. Chem. B, 2010, 114, 3655.

12. T. Li, D. Liu, and Z. Wang, Anal. Chem., 2010, 82, 3067.

13. L. P. Wu, Y. F. Li, C. Z. Huang, and Q. Zhang, Anal. Chem., 2006, 78, 5570 .

14. H. Wang, D. Chen, Y. Wei, L. Yu, P. Zhang, and J. Zhao, Spectrochim. Acta, Part A, 2011, 79, 2012.

15. Z. Yang, D. Zhang, H. Long, and Y. Liu, J. Electroanal. Chem., 2008, 624, 91.

16. Y. Zhang, L. Dong, J. Li, and X. Chen, Talanta, 2008, 76, 246.

17. A. Escarpa and M. C. González, Anal. Chim. Acta, 2001 , $427,119$.

18. X. Wang, J. Wang, and N. Yang, Food Chem., 2007, 105, 340.

19. S. Rakia, S. Petrovićb, J. Kukićb, M. Jadraninc, V. Teševićd, D. Povrenoviće, and S. Šiler-Marinković, Food Chem., 2007, 104, 830.

20. M. T. Díez, P. G. Moral, J. A. Resines, and M. J. Arín, J. Sep. Sci., 2008, 31, 2797.

21. Z. Jiang, Y. Fan, M. Chen, A. Liang, X. Liao, G. Wen, X. Shen, X. He, H. Pan, and H. Jiang, Anal. Chem., 2009, 81, 5439.

22. K. Yoosaf, B. I. Ipe, C. H. Suresh, and K. G. Thomas, J. Phys. Chem. C, 2007, 111, 12839.

23. A. Voronov, A. Kohut, S. Vasylyev, and W. Peukert, Langmuir, 2008, 24, 12587.

24. L. Kvítek, R. Prucek, A. Panácek, R. Novotný, J. Hrbáč, and R. Zbořil, J. Mater. Chem., 2005, 15, 1099.

25. Y. Yin, Z. Y. Li, Z. Zhong, B. Gates, Y. Xia, and S. Venkateswaran, J. Mater. Chem., 2002, 12, 522. 